\title{
Decrease in Asymmetrical Dimethylarginine, an Endogenous Nitric Oxide Synthase Inhibitor, in Cerebrospinal Fluid during Elderly Aging and in Patients with Sporadic Form of Amyotrophic Lateral Sclerosis
}

\author{
Chiaki Isobe $^{a, b}$ Takashi Abe $^{b}$ Yasuo Terayama ${ }^{b}$ \\ a Department of Neurology, Chitose Daiichi Hospital, Chitose, and ${ }^{b}$ Department of Neurology, \\ Iwate Medical University, Morioka, Japan
}

\section{Key Words}

Amyotrophic lateral sclerosis $\cdot$ Nitric oxide $\cdot$ Asymmetrical dimethylarginine $\cdot$ Elderly aging $\cdot$ Cerebrospinal fluid

\begin{abstract}
Background: Oxidative stress has been implicated in nervous system aging and the pathogenesis of amyotrophic lateral sclerosis (ALS) and other neurodegenerative disorders. However, the effect of asymmetrical dimethylarginine (ADMA) was previously unknown. Objective: We aimed to investigate the significance of nitric oxide (NO)-mediated neuronal death during elderly aging and in ALS. To do so, the concentration of ADMA, an endogenous NO synthase inhibitor in the cerebrospinal fluid (CSF), was determined in neurologically normal controls and in patients with ALS. Materials and Methods: There were 20 untreated patients with ALS $(\mathrm{M} / \mathrm{F}, 12 / 8)$ and 20 age-matched controls (M/F, 9/11), with a mean age $( \pm S D)$ of $66.9 \pm 9.2$ years for patients and $65.1 \pm$ 13.9 years for controls. The concentrations of ADMA and L-arginine (Arg) in the CSF of ALS patients were measured by high-performance liquid chromatography using an electrochemical detector. Control subjects were neurologically normal patients who underwent lumbar spinal anesthesia for
\end{abstract}

\section{KARGER}

Fax +4161306 1234 E-Mail karger@karger.ch www.karger.com

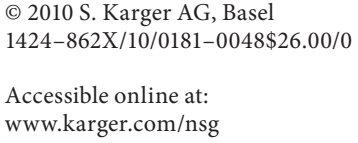

minor surgery. Results: The ADMA concentration significantly decreased with age, whereas the Arg concentration was unaltered. In patients with ALS, the ADMA concentration was significantly decreased compared with controls of a similar age $(-52 \%, p=0.0001)$. It significantly decreased with decreasing global functions of ALS $\left(r_{s}=-0.74, p<\right.$ 0.005), whereas the Arg concentration did not change. Conclusion: These findings suggest that ADMA may play an important role in regulating NO synthesis in the nervous systems of the elderly during aging and in ALS.

Copyright $\odot 2010$ S. Karger AG, Basel

\section{Introduction}

Amyotrophic lateral sclerosis (ALS) is a progressive, fatal disease characterized by the selective degeneration of upper and lower motor neurons, leading to death usually within 5 years. Approximately $5-10 \%$ of ALS is familial, with the remaining $90-95 \%$ arising sporadically (we transcribe it into ALS). Although still unknown, the pathogenesis of ALS is hypothesized to involve free radical injury [1], glutamate-mediated exitotoxicity [2] or cytoskeletal abnormalities [3]. The discovery of point 
Fig. 1. Metabolic pathway of NO, superoxide radical $\left(\mathrm{O}_{2}^{\overline{1}}\right)$ and superoxide dismutase SOD.

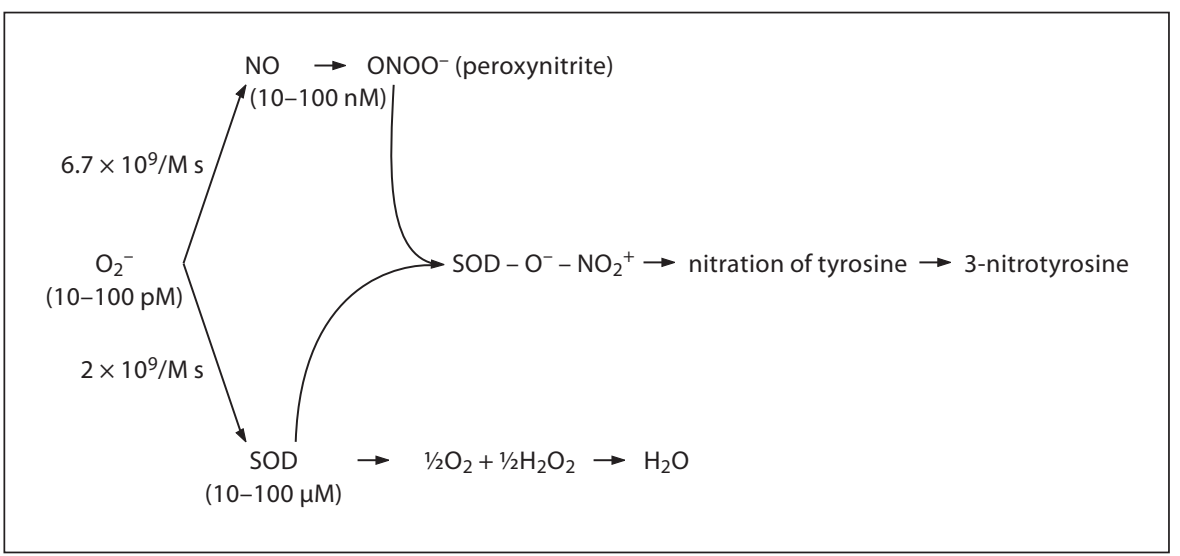

mutations and a small deletion in the $\mathrm{Cu} / \mathrm{Zn}$ superoxide dismutase gene (SOD1) on chromosome 21 in some familial ALS and ALS patients $[1,4,5]$ supports the free radical hypothesis for the pathogenesis of ALS. Superoxide radical $\left(\mathrm{O}_{2}^{\overline{2}}\right)$ reacts with nitric oxide $(\mathrm{NO})$ to form peroxynitrite $\left(\mathrm{ONOO}^{-}\right)$, which is a powerful oxidant that may directly oxidize proteins, lipids and DNA through a nitronium-like intermediate, resulting in carbonyl formation from the cleavage of side-chain and peptide bonds (fig. 1) [6]. Peroxynitrite also reacts directly with $\mathrm{Cu} / \mathrm{Zn} \mathrm{SOD}$ via a nitronium ion $\left(\mathrm{NO}_{2}^{+}\right)$intermediate that nitrates the tyrosine residues of proteins to form the stable compound 3-nitrotyrosine (fig. 1). Peroxynitrite has been reported to inhibit phosphorylation of the tyrosine residues that play an important role in intracellular signal transmission, producing hydroxyl radicals $\left({ }^{\circ} \mathrm{OH}\right)$ and killing nerve cells via a chain reaction involving lipid hyperoxidation and $\mathrm{SH}$-group oxidation $[7,8]$. The compound 3-nitrotyrosine is a highly neurotoxic molecule that is formed by a reaction between $\mathrm{NO}$, superoxide and tyrosine. As a result, 3-nitrotyrosine can be viewed as a biochemical marker of peroxynitrite-induced injury (fig. 1) [9].

NO synthase (NOS) has been localized in discrete neuronal populations in the human central nervous system. Increases in $\mathrm{NO}$ and 3-nitrotyrosine production have been reported in various neurodegenerative disorders, including ALS $[1,10,11]$, and during normal aging [12]. The methylated arginine (Arg) analogue ADMA (asymmetrical dimethylarginine) is a substance that occurs naturally in the nervous system [13], although the distribution of ADMA in the human nervous system tissues and in human cerebrospinal fluid (CSF) has not been determined in detail.
NO synthesis can be inhibited in vitro and in vivo by guanidine-substituted Arg analogues such as ADMA, which is also present in human plasma and urine [14]. This raises the possibility that guanidine-substituted Arg analogues may regulate NOS activity in the nervous system and thus modulate the NO metabolism, which may play a role in nervous system aging and the pathogenesis of ALS.

In the author's previous studies of neurodegenerative diseases, attention was focused on Alzheimer's disease. Thus far, there has not been a consensus regarding CSF ADMA levels in Alzheimer's disease patients. Previous research showed that in Alzheimer's disease, the ADMA levels in CSF decreased, but the level of Arg (a component of ADMA) did not differ from normal controls [15]. Contrarily, there was another study in which the ADMA levels in CSF did not differ from normal controls [16]. On the other hand, Arlt et al. [17] recently presented work showing that the ADMA levels in plasma increases and the ADMA levels in CSF decreases during Alzheimer's disease. Therefore, ADMA may contribute to the pathogenesis of neurodegenerative-attributed disorders. Hence, it is important to pay attention to ADMA in CSF dynamics when contemplating the mechanism of ALS. However, no study which includes ADMA levels in CSF during ALS has existed until now. To this end, our present study becomes the first report.

The aim of the present study was to determine alterations in ADMA and Arg concentrations in CSF during normal aging and in ALS patients. 


\section{Patients and Methods}

\section{Patients}

The subjects were 20 untreated patients with ALS (M/F, 8/12) and 20 age-matched controls (M/F, 9/11), mean age ( \pm SD) 66.9 \pm 9.2 and $65.1 \pm 13.9$ years, respectively. Control subjects were neurologically normal patients who underwent lumbar spinal anesthesia for minor surgery. Throughout this study, ALS was diagnosed based on neurological history, neurological examination and laboratory testing. Diagnostic criteria for ALS were made according to El Escorial World Federation of Neurology criteria for the diagnosis of ALS [18]. Global ALS dysfunction was assessed based on ALSFRS-R (the revised Amyotrophic Lateral Sclerosis Functional Rating Scale) [19], which is derived by adding disability scores in 13 areas, with a maximum score of 42. In patients with ALS, the duration of the illness had been 4.0 \pm 2.7 years and the mean ALSFRS-R score was $16.5 \pm 4.5$. All patients were admitted to a hospital and were maintained on a standard diet.

All patients or their families provided informed consent, and the study protocol was approved by the Committee for Ethics in Biomedical Research at Iwate Medical University (Morioka, Japan).

\section{CSF Analysis}

CSF was obtained by lumbar puncture with the patients in a lateral decubitus position, between 9:00 and 10:00 a.m., after overnight bed-rest and before breakfast. The first (3-ml) CSF sample was used for general examination (we confirmed these samples were without erythrocyte contamination), and the next (1-ml) CSF samples drawn from the patients were rapidly frozen and stored at $-80^{\circ} \mathrm{C}$ prior to being assayed.

Cell counts and protein concentrations in CSF were within the normal range in both ALS patients and normal controls (1.6 \pm $1.1 \mathrm{~mm}^{3}$ and $35.2 \pm 5.2 \mathrm{mg} / \mathrm{dl}, 1.4 \pm 1.2 \mathrm{~mm}^{3}$ and $29.4 \pm 8.2 \mathrm{mg} /$ dl, respectively).

\section{ADMA Assay}

CSF samples were passed through a 10,000 NMWL ultrafilter (UFC LGC00; Japan Millipore Ltd., Tokyo, Japan), and concentrations of free ADMA and Arg were determined according to the method described by Donzanti and Yamamoto [20], with some modifications. The working derivatizing solution was prepared by diluting $54 \mathrm{mg} o$-phthalaldehyde in $1 \mathrm{ml}$ of methanol with $10 \mu \mathrm{l}$ of $\beta$-mercaptoethanol and $9 \mathrm{ml}$ of $0.10 \mathrm{M}$ sodium borate ( $\mathrm{pH}$ 9.5). Precolumn amino acid derivatization was accomplished by mixing $75 \mu \mathrm{l}$ of the CSF sample with $20 \mu \mathrm{l}$ of the working $o$-phthalaldehyde/ $\beta$-mercaptoethanol reagent for exactly $2 \mathrm{~min}$ prior to injection into the analytical column. The mobile phase consisted of $0.10 \mathrm{M} \mathrm{NaH}_{2} \mathrm{PO}_{4}$ and $25 \%$ methanol and was adjusted to $\mathrm{pH} 6.75$ with $\mathrm{NaOH}$. ADMA and Arg were separated by injection of $30-\mu \mathrm{l}$ volumes of the reaction mixture into an NBS $\mathrm{C}_{18}$ reversed-phase column $(150 \times 4.6 \mathrm{~mm}$; MC Medical, Tokyo, Japan). For sample analysis, we used a coulometric electrochemical detector (Coulochem II Model 5200; ESA Inc., Bedford, Mass., USA). The electrode potentials were maintained at $0.45 \mathrm{~V}$ for the guard cell, $0.25 \mathrm{~V}$ for detector I, and $0.4 \mathrm{~V}$ for detector II. The detection limits for ADMA and Arg were both $0.001 \mu l$. The standards for ADMA and Arg were obtained from Sigma Chemical Co. (St. Louis, Mo., USA).

Decrease of ADMA in the CSF from ALS Patients

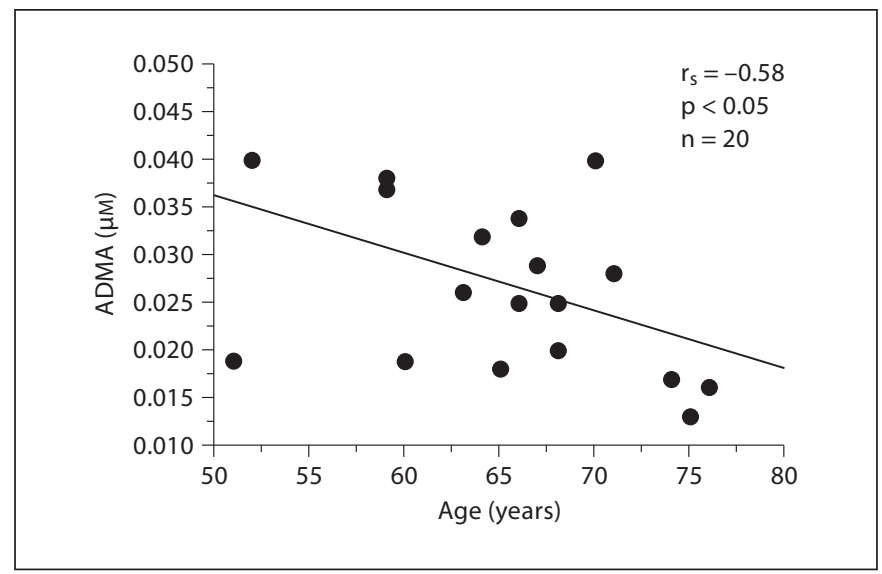

Fig. 2. Concentrations of ADMA as a function of elderly aging in control subjects.

\section{Statistical Analysis}

Statistical analysis was performed using the nonparametric Mann-Whitney U test or the Spearman's rank correlation coefficient $\left(r_{s}\right)$ with StatView 5.0 software (SAS Institute Inc., Cary, N.C., USA). $\mathrm{p}<0.05$ was considered to be statistically significant.

\section{Results}

In controls, the ADMA concentration ranged from 0.015 to $0.042 \mu \mathrm{l}$, and the Arg concentration ranged from 29.4 to $54.6 \mu \mathrm{M}$ (data not shown). Within these control ranges, the ADMA concentration significantly decreased with advancing age $\left(r_{s}=-0.58, p<0.05\right.$; fig. 2$)$. In contrast, the Arg concentration did not significantly change with elderly aging $\left(r_{s}=0.14, p=0.54\right)$. The Arg concentration in patients with ALS did not significantly differ from that of age-matched controls $(42.6 \pm 8.2$ vs. $39.4 \pm 7.0$ $\mu \mathrm{l}$, respectively). However, the ADMA concentration was significantly lower in the ALS patients than in their agematched controls $(0.012 \pm 0.004$ vs. $0.027 \pm 0.006 \mu \mathrm{l}$, respectively; $\mathrm{p}=0.0001$; fig. 3 ) The ADMA concentration did not correlate with duration of illness $\left(\mathrm{r}_{\mathrm{s}}=-0.10, \mathrm{p}<\right.$ 0.71 ), but it showed a significant negative correlation with ALSFRS-R scores $\left(r_{s}=-0.74, p<0.005\right.$; fig. 4$)$.

\section{Discussion}

The brain and spinal cord tissues are constantly at risk of being damaged by reactive oxygen species, given the large amount of oxygen consumption that occurs in the 


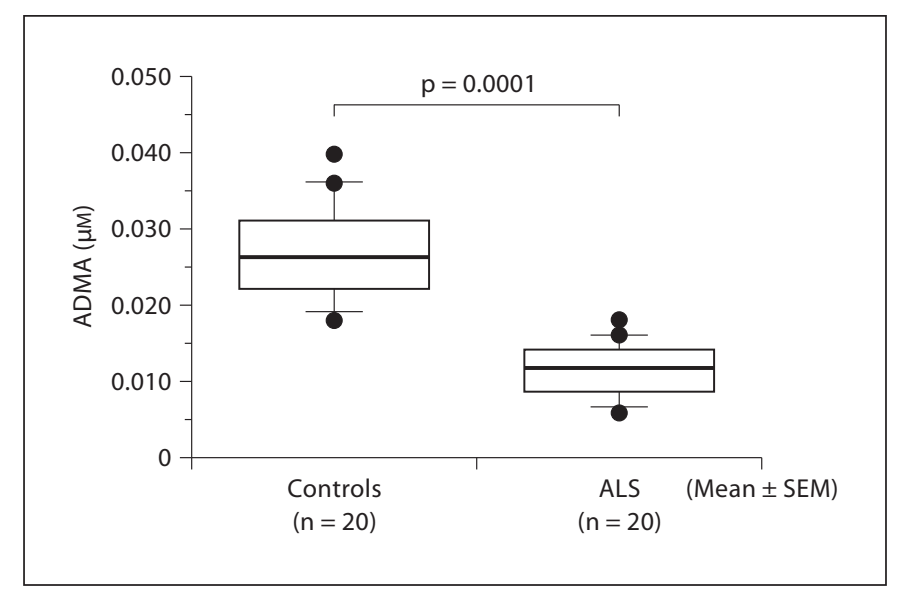

Fig. 3. Concentrations of ADMA (scattergram and means \pm SEM) in ALS patients and controls.

brain and spinal cord, including the motor neuron system. The threats of oxidative damage comes from a variety of sources, any or all of which can be activated by oxidative stress.

Regarding reactive oxygen species and ALS, there are numerous supportive previous studies lending support to the contribution of reactive oxygen species to ALS. A pathological study showed that glutathione peroxidase activity deteriorated in the precentral cortex in autopsies of ALS afflicted cerebrum [21]. Immunohistochemical studies have demonstrated the upregulated stainability of 8-hydroxy-2'-deoxyguanosine, a DNA nucleic acid injury marker of brain during autopsy of the ALS motor cortex and spinal cord [22]. In our study of living patients with ALS, 3-nitrotyrosine levels increased in CSF [11].

The reaction speed of NO is faster than SOD scavenging speed for $\mathrm{O}_{2}^{\overline{2}}$ even in the physiological state (fig. 1). We consider that perhaps the reaction speed of NO becomes more significant during the pathogenetic condition of ALS, due to the increasing 3-nitrotyrosine levels in the CSF seen in living patients with ALS (fig. 1) [11].

The present result demonstrated that ADMA was detected in the CSF and that the levels of ADMA in the CSF significantly decreased with elderly aging and in patients with ALS (-52\%, compared to controls). Methylated Arg analogues such as ADMA can inhibit NOS and may play an important role in regulating signal transduction through the NO system. It has been reported that ADMA (but not symmetrical dimethylarginine) accumulation [14] acts as an endogenous inhibitor of NOS in vitro and in vivo, and this suggests that a similar mechanism for

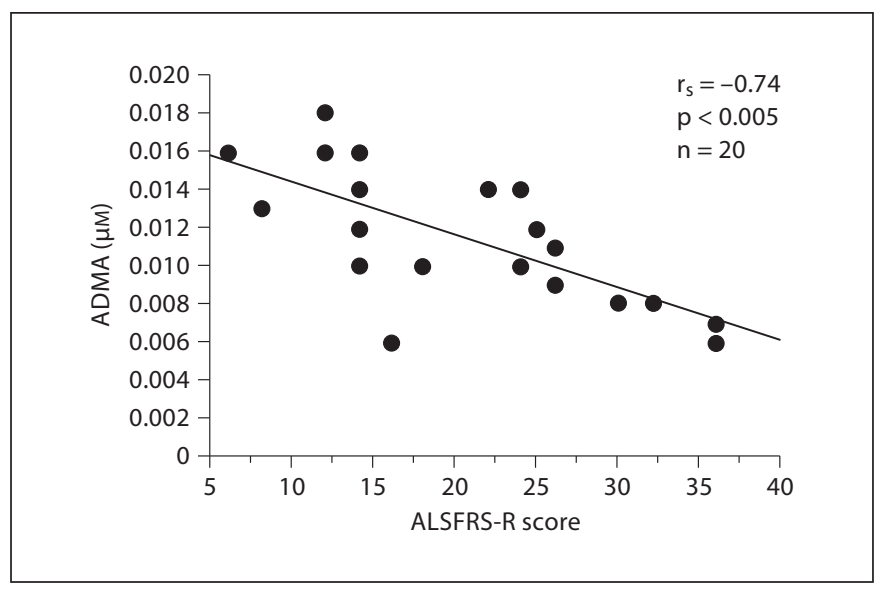

Fig. 4. Concentrations of ADMA in ALS patients as a function of ALSFRS-R score.

controlling NO synthesis may exist in the nervous system and could be related to the pathogenesis of ALS. Transmethylation is catalyzed by S-adenosyl-L-methionine [23]. Previous studies reported reduced S-adenosyl-L-methionine levels in the CSF [24] and nervous system [25] of ALS patients. Such a reduction in S-adenosyl-L-methionine levels in the CSF and nervous system of ALS patients may cause a decrease in ADMA concentrations in the CSF and nervous system. In our previous study, 3-nitrotyrosine concentrations in the CSF increased with advancing age among elderly patients [12]. This increase in 3-nitrotyrosine with elderly aging may result from increased NOS activity $[26,27]$ due to a decrease in ADMA.

The present significant decrease in ADMA in patients with ALS is consistent with studies reporting increases in NADPH diaphorase- and 3-nitrotyrosine-positive neurons in the ALS nervous system $[1,4,5]$, implicating $\mathrm{NO}$ and $\mathrm{ONOO}^{-}$in the pathogenesis of ALS. The fact that NOS-containing neurons are relatively spared in ALS [28] and the activity of $\mathrm{Cu} / \mathrm{Zn} \mathrm{SOD}$ (which reacts with $\mathrm{ONOO}^{-}$to nitrate tyrosine residues) is decreased in the ALS nervous system [29] suggests that the increase in 3 -nitrotyrosine is due to an increase in production of $\mathrm{NO}$ and oxidation of $\mathrm{NO}$ to $\mathrm{ONOO}^{-}$during ALS. Whereas 3-nitrotyrosine concentrations in the CSF of ALS patients remarkably increased with disease progression in our previous study [11], ADMA decreased significantly with increasing severity of ALS in the present study. Both results suggest that NOS activity increases with disease development, resulting in an increased production of $\mathrm{NO}, \mathrm{ONOO}^{-}$and 3-nitrotyrosine. 
As a therapeutic possibility of the prospective future of ALS associated with our present study, Ito et al. [30] presented that edaravone (a free radical scavenger, which is being widely used for cerebral ischemia in Japan) significantly slowed motor decline of ALS in a mouse model. Moreover, the remaining motor neurons were significantly preserved, and the 3-nitrotyrosin/tyrosine ratios were reduced dose-dependently.

In our present study, we showed, for the first time, that the ADMA levels in CSF decreased in real living ALS patients. However, the putative role of decrease in ADMA levels in ALS cannot be entirely demonstrated given the pivotal role of ADMA in cellular metabolism. Treatment to scavenge free radicals may progress more in the future. Further study is warranted to determine whether the finding in the present results reflects changes in nervous system tissues. We expect a prospective, large scale study with unselected ALS patients is required for a definitive ascertainment.

\section{Conclusion}

ADMA levels in CSF decrease significantly with elderly aging and are also significantly lower in patients with ALS than in controls. These findings suggest that ADMA may play an important role in regulating NO synthesis during elderly aging of the nervous system and in the pathogenesis of the sporadic form of ALS.

\section{Acknowledgements}

This study was supported in part by the Ministry of Education, Science and Culture and the Ministry of Health, Labor and Welfare in Japan.

\section{References}

1 Beal FM, Ferrante RJ, Browne SE, Mattews RT, Kowall NW, Brown RH Jr: Increased 3-nitrotyrosine in both sporadic and familial amyotrophic lateral sclerosis. Ann Neurol 1997;42:646-654.

2 Garthwaite J: Glutamate, nitric oxide and cell-cell signaling in the nervous system. Trends Neurosci 1991;14:75-82.

3 Collard JF, Côté F, Julien JP: Defective axonal transport in a transgenic mouse model of amyotrophic lateral sclerosis. Nature 1995; 375:61-64.

4 Jones CT, Swingler RJ, Brock DJ: Identification of a novel SOD1 mutation in an apparently sporadic amyotrophic lateral sclerosis patients and the deletion of IIe $113 \mathrm{Thr}$ in three others. Hum Mol Genet 1994;3:649650 .

5 Uchino M, Ando Y, Tanaka Y, Nakamura T, Uyama E, Mita S, Murakami T, Ando M: Decrease in $\mathrm{Cu} / \mathrm{Zn}$-and $\mathrm{Mn}$ superoxide dismutase activity in brain and spinal cord of patients with amyotrophic lateral sclerosis. J Neurol Sci 1994;127:61-67.

-6 Ischiropoulos H, Zhu L, Chen J, Tsai M, Martin JC, Smith CD, Beckman JS: Peroxynitrite-mediated tyrosine nitration catalyzed by superoxide dismutase. Arch Biochem Biophys 1992;298:431-437.

7 Dawson TM, Dawson VL, Synder SH: A novel neuronal messenger molecule in brain: the free radical, nitric oxide. Ann Neurol 2002; 32:297-311
8 Lipton SA, Choi YB, Pan ZH, Lei SZ, Chen HS, Sucher NJ, Loscalzo J, Singel DJ, Stamler JS: A redox-based mechanism for the neuroprotective and neurodestructive effects of nitric oxide and related nitroso-compounds. Nature 1993;364:626-632.

9 Beckman JS, Carson M, Smith CD, Koppenol WH: ALS, SOD and peroxynitrite. Nature 1993;364:584

10 Abe K, Pan LH, Watanabe M, Kato T, Itoyama Y: Induction of nitrotyrosine-like immuno-reactivity in the lower motor neuron of amyotrophic lateral sclerosis. Neurosci Lett 1995; 199:152-154

- 11 Tohgi H, Abe T, Yamazaki K, Murata T, Ishizaki E, Isobe C: Remarkable increase in cerebrospinal fluid 3-nitrotyrosine in patients with sporadic amyotrophic lateral sclerosis. Ann Neurol 1999;46:129-131.

12 Tohgi $\mathrm{H}$, Abe T, Yamazaki K, Murata T, Ishizaki E, Isobe C: Alteration of 3-nitorotyrosine concentration in the cerebrospinal fluid during aging and in patients with $\mathrm{Alz}$ heimer's disease. Neurosci Lett 1999;269:5254.

13 Kotani K, Shu-ichi U, Sano A, Kakimoto Y: Isolation and identification of methylarginines from bovine brain. J Neurochem 1992; 58:1127-1129.

14 Vallance P, Leone A, Calver A, Colliner J, Moncada S: Accumulation of an endogenous inhibitor of nitric oxide synthesis in chronic renal failure. Lancet 1992;339:572-575.
15 Abe T, Tohgi H, Murata T, Isobe C, Sato C: Reduction in asymmetrical dimethylarginine, an endogenous nitric oxide synthase inhibitor, in the cerebrospinal fluid during aging and in patients with Alzheimer's disease. Neurosci Lett 2001;312:177-179.

16 Mulder C, Wahlund LO, Blomberg M, de Jong S, van Kamp GJ, Scheltens P, Teerlink T: Alzheimer's disease is not associated with altered concentrations of the nitric oxide synthase inhibitor asymmetric dimethylarginine in cerebrospinal fluid. J Neural Transm 2002;109:1203-1208.

$\checkmark 17$ Arlt S, Schulze F, Eichenlaub M, Maas R, Lehmbeck JT, Schwedhelm E, Jahn H, Böger RH: Asymmetrical dimethylarginine is increased in plasma and decreased in cerebrospinal fluid of patients with Alzheimer's disease. Dement Geriatr Cogn Disord 2008;26: 58-64.

18 Brooks BR: El Escorial World Federation of Neurology criteria for the diagnosis of amyotrophic lateral sclerosis. Subcommittee on Motor Neuron Diseases/Amyotrophic Lateral Sclerosis of the World Federation of Neurology Research Group on Neuromuscular Diseases and the El Escorial 'Clinical Limits of Amyotrophic Lateral Sclerosis' workshop contributors. J Neurol Sci 1994; 124(Suppl):96-107.

19 The Amyotrophic Lateral Sclerosis Functional Rating Scale. Assessment of activities of daily living in patients with amyotrophic lateral sclerosis. The ALS CNTF treatment study (ACTS) phase I-II Study Group. Arch Neurol 1996;53:141-147. 
20 Donzanti BA, Yamamoto BK: An improvement and rapid HPLC-ECD method for the isocratic separation of amino acid neurotransmitters from brain tissue and microdialysis perfusates. Life Sci 1988;43:913-922.

-21 Przedborski S, Donaldson D, Jakowec M, Kish SJ, Guttman M, Rosoklija G, Hays AP: Brain superoxide dismutase, catalase, and glutathione peroxidase activities in amyotrophic lateral sclerosis. Ann Neurol 1996; 39:158-165.

22 Ferrante RJ, Browne SE, Shinobu LA, Bowling AC, Baik MJ, MacGarvey U, Kowall NW, Brown RH Jr, Beal MF: Evidence of increased oxidative damage in both sporadic and familial amyotrophic lateral sclerosis. J Neurochem 1997;69:2064-2074.
23 Syed SK, Kim S, Paik WK: Identification of the S-adenosyl-L-methionine binding site of protein-carboxyl O-methyltransferase using 8-azido-S-adenosyl-L-methionine. Biochemistry 1999;32:2242-2247.

24 Dubey M, Shea TB: Potentiation of arsenic neurotoxicity by folate deprivation: protective role of S-adenosyl methionine. Nutr Neurosci 2007;10:199-204.

25 Lou JS: Fatigue and depression are associated with poor quality of life in ALS. Neurology 2003;14:122-123.

26 McCann SM: The nitric oxide hypothesis of brain aging. Exp Gerontol 1997;32:431-440.

27 Olken NM, Marletta MA: NG-Methyl-L-arginine function as an altermate substrate and mechanism-based inhibitor of nitric oxide synthase. Biochemistry 1993;32:96779685.
28 Aguila MC, Kuljis RO: Degeneration of NOsynthesizing cerebrocortical neurons in transgenic mice expressing mutated superoxide dismutase is not due to elevated nitric oxide levels. Brain Res 1999;816:241-244.

29 Deng HX, Hentati A, Tainer JA, Iqbal Z, Cayabyab A, Hung WY, Getzof ED, Hu P, Herzfeldt B, Ross RP, et al: Amyotrophic lateral sclerosis and structural defects in $\mathrm{Cu}, \mathrm{Zn}$ superoxide dismutase. Science 1993;261: 1047-1051.

30 Ito H, Wate R, Zhang J, Ohnishi S, Kaneko S, Nakano S, Kusaka H: Treatment with edaravone, initiated at symptom onset, slows motor decline and decreases SOD1 deposition in ALS mice. Exp Neurol 2008;213:448-455. 